more frequent bowel actions than euthyroid subjects, though only a minority $(21.4 \%)$ had noticed any change. Conversely, patients with myxoedema have a tendency to constipation, though only one complained of it. A bowel action less than once daily could be a useful pointer against the diagnosis of hyperthyroidism.

We acknowledge and thank the consultant physicians and surgeons at the Middlesex Hospital who referred patients for investigation in the department. We also thank Dr. E. S. Williams for his help and encouragement and Sister L. I. Pope and staff for technical help in carrying out the radioiodine uptake tests.

\section{References}

Connell, A. M., Hilton, C., Irvine, G., Lennard-Jones, J. E., and Misiewicz, J. J. (1965). British Medical fournal, 2, 1095

Crooks, J., Murray, I. P. C., and Wayne, E. J. (1959). Quarterly fournal of Medicine, 28, 211 .

Scarf, M. (1936). Fournal of Laboratory and Clinical Medicine, 21, 1253.

Shirer, J. W. (1933). American fournal of Medical Science, 186, 73.

Wayne, E. J. (1954). British Medical fournal, 1, 411.

\title{
Subdural Haematoma Simulating Primary Subarachnoid Haemorrhage
}

\author{
PETER GORTVAI, D. I. ANAGNOSTOPOULOS
}

British Medical fournal, 1971, 1, 323-324

\section{Summary}

In three cases of subdural haematoma which resembled primary subarachnoid haemorrhage the diagnosis was made only by cerebral angiography. Angiography should be done whenever the diagnosis is in doubt.

\section{Introduction}

Subdural haematoma may cause sudden severe headache followed by transient loss of consciousness. This article describes three such cases clinically indistinguishable from primary subarachnoid haemorrhage caused by rupture of an intracranial aneurysm or an arteriovenous malformation.

\section{Case Reports}

Case 1.-A man of 54 was admitted to hospital stating that three weeks previously severe bifrontal headache had suddenly developed. He stayed at home, but the headache did not improve. On examination he was very drowsy, dysphasic, and disorientated, with pronounced neck rigidity, right hemiparesis, and bilateral extensor plantar responses. Lumbar puncture yielded xanthochromic fluid, red cells $27,000 / \mathrm{mm}^{3}$, white cells $6,000 / \mathrm{mm}^{3}$, with $95 \%$ lymphocytes and $5 \%$ polymorphs, sugar $90 \mathrm{mg} / 100$ $\mathrm{ml}$, and protein $45 \mathrm{mg} / 100 \mathrm{ml}$. He was transferred to our neurosurgical unit with the provisional diagnosis of subarachnoid haemorrhage. $X$-ray films of the skull and chest showed nothing abnormal and the peripheral blood picture was normal. Bilateral carotid angiography showed a right-sided subdural haematoma but no aneurysm or vascular malformation. The subdural haematoma was evacuated through a right parietal and right frontal burrhole, and a parietal subdural drain was left for 48 hours. The patient made a quick and satisfactory recovery, and when last seen, 10 months after operation, he was back at work as a skilled artisan, free from abnormal signs and symptoms.

Case 2.-A woman of 59 was admitted to hospital disorientated and incontinent. During the two weeks before admission she had two sudden severe attacks of headache with vomiting and was drowsy for the last three days. Neck rigidity, slight right

Regional Centre for Neurology and Neurosurgery, Oldchurch Hospital, Romford, Essex

PETER GORTVAI, M.CHIR., F.R.C.S., Consultant Neurosurgeon D. I. ANAGNOSTOPOULOS, DIP.MED., Neurosurgical Registrar hemiparesis, and bilateral extensor plantar responses were noted. Lumbar puncture yielded blood-stained fluid with a xanthochromic supernatant. She was transferred to our neurosurgical unit with the diagnosis of subarachnoid haemorrhage. Skull and chest $x$-ray films showed nothing abnormal and the peripheral blood picture was normal. Bilateral carotid angiography showed a right-sided subdural haematoma, but no aneurysm or angioma. The haematoma was evacuated through a posterior parietal and temporal burrhole. The subdural space was drained for 48 hours. Within a few days she was free from signs and symptoms, and when last seen, four months postoperatively, she was in excellent health.

Case 3.-A woman of 59 had had rheumatic fever in childhood and had developed mitral stenosis. Mitral valvotomy had been performed two years previously and she was given digoxin, frusemide with oral potassium supplement, and phenindione. Two weeks before admission to our unit she suddenly developed headache and lost consciousness for an hour. Six days before admission she again complained of sudden headache with vomiting and photophobia. Lumbar puncture yielded blood-stained fluid with xanthochromic supernatant. On admission she was correctly orientated but drowsy, and her neck was stiff. Left hemiparesis and bilateral extensor plantar responses were present. The heart was fibrillating and there was a rumbling mid-diastolic murmur over the apex of the heart. There were no clinical signs of congestive cardiac failure. Chest $x$-ray examination showed enlargement of the left auricle; the lung fields were clear. Skull $x$-ray films showed nothing abnormal. The peripheral blood picture was normal. Quick's prothrombin test gave the same time as the control 10 days after phenindione was stopped. An electroencephalogram showed only minor generalized disturbance. A brain scan with technetium-99 indicated increased activity along the lateral edge of the brain in the right frontotemporal area suggestive of a subdural haematoma. Bilateral carotid angiography showed a right subdural haematoma. The haematoma was evacuated through a right temporal and right parietal burrhole and the subdural space was drained for $\mathbf{4 8}$ hours. The headache improved immediately. The hemiparesis cleared up more slowly. When last seen, three months postoperatively, she was free from symptoms and abnormal neurological signs.

\section{Discussion}

Two cases of subdural haematoma with a history of dramatic suddenness were described by Clark and Gooddy (1953). As these authors pointed out, the differentiation of subdural from subarachnoid haemorrhage on the grounds of slower onset of the former, as suggested by Richardson and Hyland (1941), is not valid in all cases.

A history of significant head injury is often absent in cases of subdural haematoma. Jelsma (1930) obtained a history of 
injury sufficient to produce unconsciousness in only $25 \%$ of his cases. Neck stiffness and positive Kernig's sign with or without further abnormal neurological signs may be found with a subdural haematoma or with primary subarachnoid haemorrhage. Blood-stained cerebrospinal fluid can be withdrawn in subarachnoid haemorrhage and is commonly seen with subdural haematoma. The fluid was blood-stained in all our cases.

A subdural haematoma may form when bleeding is primarily subarachnoid (Voris, 1946; Scott, 1949). Angiography did not show an aneurysm in our cases. While this does not exclude the presence of an aneurysm absolutely, it makes it unlikely, and the benign clinical course after operation supports the absence of a primary vascular lesion We believe that in our cases the subdural space was the primary site of bleeding, probably caused by past trivial trauma, as discussed by Trotter (1914). In Case 3 the subdural haematoma may have arisen as a complication of anticoagulant therapy. Patients suffering from subdural haematoma while on anticoagulant medication were reported by Chawla (1968).

Because the diagnosis could be made only on carotid angiography, we recommend that all cases reminiscent of the syndrome of primary subarachnoid haemorrhage be examined by cerebral angiography lest an easily treatable lesion be overlooked.

\section{References}

Chawla, J. C. (1968). Guy's Hospital Reports, 117, 75.

Clark, E. S., and Gooddy, W. (1953). Brain, 76, 266.

Jelsma, F. (1930). Archives of Surgery, 21, 128

Richardson, J. C., and Hyland, H. H. (1941). Medicine, 20,

Scott, M. (1949). Fournal of the American Medical Association, 141, 596.

Trotter, W. (1914). British fournal of Surgery, 2, 271.

Voris, H. C. (1946). Fournal of the American Medical Association, 132, 686.

\section{PRELIMINARY COMMUNICATIONS}

\section{Importance of Central Vasomotor Effects in Angiotensin-induced Hypertension}

\author{
G. C. SCROOP， FRANCES KATIC， M. D. JOY, \\ R. D. LOWE
}

British Medical fournal, 1971, 1, 324-326

\section{Summary}

Ablation of the areas postrema in $\mathbf{1 0}$ dogs caused a highly significant reduction in the pressor response to intravenous infusions of angiotensin yet was without significant effect on the pressor response to intravenous infusions of noradrenaline. The reduction in the pressor response to angiotensin is almost certainly due to abolition of the specific central autonomic effects of the hormone which are dependent on the integrity of the areas postrema. It is suggested that this central effect also contributes to the cardiovascular response to endogenous angiotensin.

\section{Introduction}

Angiotensin has a powerful direct constrictor action on blood vessels which may make an important contribution to the hypertension seen in those patients with raised plasma levels of renin or angiotensin. The blood vessels of such patients, however, are often relatively unresponsive to the direct action of the hormone (Scroop and Whelan, 1968a), and the degree of hypertension that exists is often not well correlated with the estimated plasma levels of renin or angiotensin. For these and other reasons it has been suggested that other angioten-

Department of Medicine, St. Thomas's Hospital, London S.E.1

G. C. SCROOP, M.D., C. J. Martin Travelling Fellow of the National Health and Medical Research Council of Australia

FRANCES KATIC, Research Assistant

M. D. JOY, M.B., M.R.C.P., Research Fellow

R. D. LOWE, M.D. M.R.C.P., Senior Lecturer sin-dependent mechanisms may be involved in maintaining the hypertension.

The elucidation of a variety of autonomic effects of angiotensin in recent years, both in man (Scroop and Whelan, 1966; Henning and Johnsson, 1967) and in animals (Bickerton and Buckley, 1961; Yu and Dickinson, 1965; Zimmerman, 1967), together with the demonstration of a significant neurogenic component in the chronic phase of experimental hypertension (McCubbin and Page, 1963), suggest that such actions may well make an important contribution to the hypertensive effect of the hormone. Attempts to demonstrate such a contribution in man, however, have not been successful (Laurence and Nagle, 1963; Scroop and Whelan, 1968b) largely for technical reasons.

Scroop and Lowe (1968) described a very sensitive and entirely nervously-mediated pressor effect of angiotensin in the anaesthetized greyhound in response to vertebral artery infusions at rates as low as $0.1 \mathrm{ng} / \mathrm{kg} / \mathrm{min}$ (Lowe and Scroop, 1969). Joy and Lowe (1970) were able to abolish this response by thermocoagulation of the areas postrema in the greyhound while at the same time preserving the specific central hypertensive effects of other vasoactive substances. The response to carotid artery occlusion was unmodified by this procedure (Joy and Lowe, 1970), suggesting that both the effector autonomic pathways and the baroreceptor reflexes are intact. Since ablation of the areas postrema abolishes the central effect of angiotensin, we have used this technique to determine the contribution of this central effect in the overall response to the hormone. The results clearly show a significant reduction in the pressor response following this procedure, and the importance of this finding with regard to the cardiovascular effects of endogenously generated angiotensin is discussed.

\section{Methods}

Experiments were carried out in 10 greyhounds which were premedicated with morphine $(2 \mathrm{mg} / \mathrm{kg}$ intravenous injection) and anaesthetized with alpha chloralose $(125 \mathrm{mg} / \mathrm{kg}$ intravenously) and which were artificially ventilated throughout the experiments.

Arterial pressure and heart rate were recorded on a Grass Polygraph, standard techniques being used. Vertebral artery infusions of angiotensin were made through a non-obstructing 